\title{
Differences in acquisition of environmental data in strongly impacted marine sediments using gravity and vibro corers: the case-study of Augusta Harbor (Eastern Sicily, Italy)
}

\author{
E. Romano ${ }^{1 *}$, L. Bergamin ${ }^{1}$, M. Celia Magno ${ }^{1}$, A. Ausili ${ }^{1}$, Gabellini M. ${ }^{1}$, I.W. Croudace ${ }^{2}$ \\ ${ }^{1}$ ISPRA. Institute for Environmental Protection and Research, Via V. Brancati 60, 00144 Rome, Italy \\ ${ }^{2}$ GAU- Radioanalytical Laboratories, University of Southampton, National Oceanography Centre, \\ Southampton, UK \\ * Corresponding author: elena.romano@isprambiente.it
}

\begin{abstract}
Sediment cores are used to reconstruct the chronological evolution of contamination in impacted areas while deep core levels may be considered as reference conditions for the assessment of environmental status. For this purpose, the collection of undisturbed cores is essential. Vibro and gravity corers are the most used devices for environmental research. In this study, chemical (Ba, Hg and PCBs) and grain size data obtained by means of gravity (SW-104) and vibro (Rossfelder ${ }^{\circledR}$ ) corer from 3 stations of the heavily contaminated Augusta harbor (Sicily, Italy) were considered. Their vertical profiles were compared considering the different technical characteristics of corers, in order to highlight differences in data acquisition. Results showed that, for areas characterized by high sedimentation rates, the vibrocorer is the best choice for the higher penetration capacity. No significant differences were recognized for sediment compaction and potential downward drag of the contaminants.
\end{abstract}

\section{Keywords:}

Marine sediments; Contaminated areas; Gravity corer; Vibrocorer; Environmental data.

\section{Introduction}

The environmental characterization of marine coastal areas, especially if impacted by human activity, requires a careful sampling strategy of the sediments. The chemical and textural characteristics of sediments from superficial and deep levels are very important parameters to be considered in the evaluation of potential anthropogenic impact on marine coastal systems, because they preserve the record of sedimentary and chemical input. Sediment core is the best choice for this kind of studies because it preserves the record of sedimentary and chemical input, due both to natural and anthropogenic factors. Deep core levels reflect environmental conditions before the impact and, consequently, they may be used as reference conditions for the assessment of the environmental status (Guo and Yang, 2016). Due to these features, sediment cores are also the best choice for determining the background concentrations of metals and trace elements in marine sediments (Romano et al., 2015). In this context, the sampling method is of basic importance to acquire reliable data, because the collected samples should be virtually undisturbed, while any devices could be the cause of some disturbance during penetration into the sea bottom.

Two replicate cores from three stations (AU3, AU9 and AU10) of the coastal area of the Augusta harbor, sampled during a comprehensive environmental characterization finalized to identify extent and chronology of contamination, were considered for this study (Fig. 1).

Aim of this study is to highlight advantages and disadvantages of both gravity and vibro corer for data acquisition finalized to the historical reconstruction of contamination patterns. This goal is achieved taking into account different technical characteristics and different physical principles used for sediment 
penetration, and by comparing vertical profiles of sediment parameters such as grain size and heavy metal concentration, obtained using the two devices.

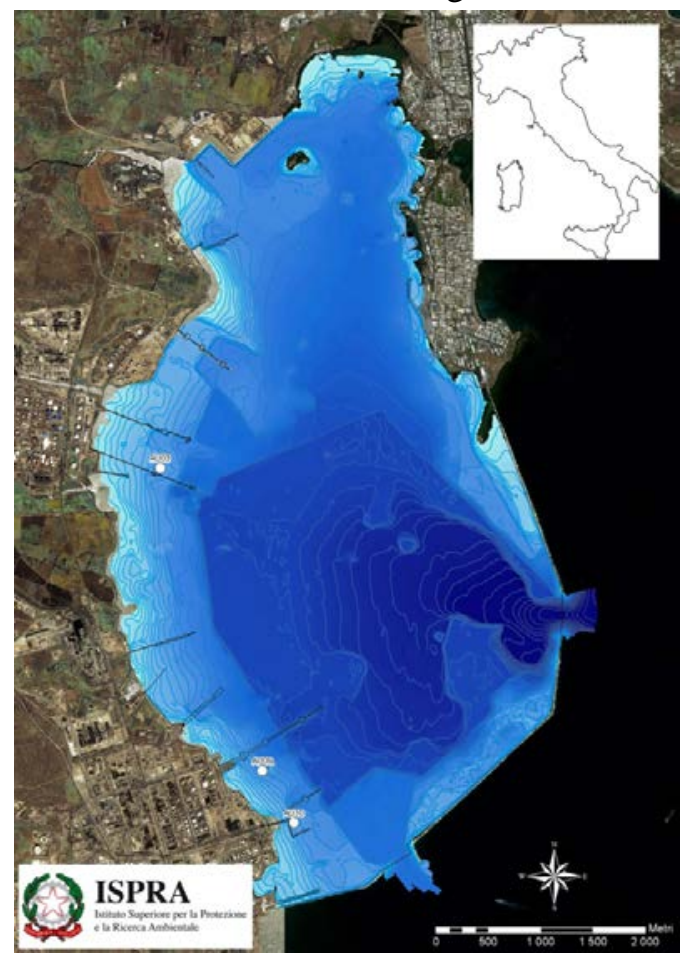

Figure 1. Study area and sampling stations.

\section{Study area}

The Augusta bay (Sicily, Mediterranean Sea) is an important harbour area of the Eastern Sicilian coast. It developed into a significant industrial harbour from the 1950s onward and became a major processing centre for petrochemicals and chemical industry that are located in the southern sector. It is also one of the most important Italian harbors for bunker operations, ship repairing and maintenance, and loading and unloading of goods. Most industries such as chemical and petrochemical plants, oil refineries and electric power plants have impacted the area for several decades (Croudace et al., 2015) but one of the most important contributors was the Mercury Cell Chlor-Alkali Plant (MCCAP) that operated from 1958 to 2003. Recent studies of the area have established the vertical and spatial distributions of some metals (Hg and Ba), PAHs, HCB and PCBs and found the highest concentrations in the southern sector. Particularly, Hg was found up to $190 \mathrm{mg}$ $\mathrm{kg}^{-1}$ d.w. in superficial sediments, and exceeding $500 \mathrm{mg} \mathrm{kg}^{-1}$ d.w. in the upper $50 \mathrm{~cm}$ sediment interval (ICRAM, 2008; Romano et al., 2009; 2013; Croudace et al., 2015). One study argued that the high Hg content in the Harbour sediments are important contributors for this element to the Mediterranean Sea, with Hg output of $0.162 \mathrm{kmol} \mathrm{y}^{-1}$ (Sprovieri et al., 2011).

The Augusta bay is a semi-closed basin with two main inlets, in the central and southern parts of the harbor, which ensure the connection with the open sea (Fig. 1). The inner part of the harbour area is influenced, in the northern and central sectors, by the runoff from the several streams, which drain mainly MesozoicQuaternary carbonatic rocks (ISPRA, 2011). The characteristic of harbour sediments reflects the local geology, soil composition and the hydrological catchment. The local geology consists of carbonate sequences (Cretaceous to Quaternary Age), with volcanoclastic and volcanic interbedded horizons along with muddy sediments and calcarenites (Nigro and Renda, 2000; Scicchitano et al., 2007). In the southernmost part of the harbour patchy areas of emerging rocky substrate are present nearshore (Anonymous, 1992; 1995). 
The harbour sediments range between sand and silty clay (Fig. 2). Silt and clay are the prevailing fractions, with the highest values in the northern sector, while sand reaches higher values nearshore, in the central sector, and close to the southern inlet; gravel is generally absent or very scarce (Celia Magno et al., 2012).

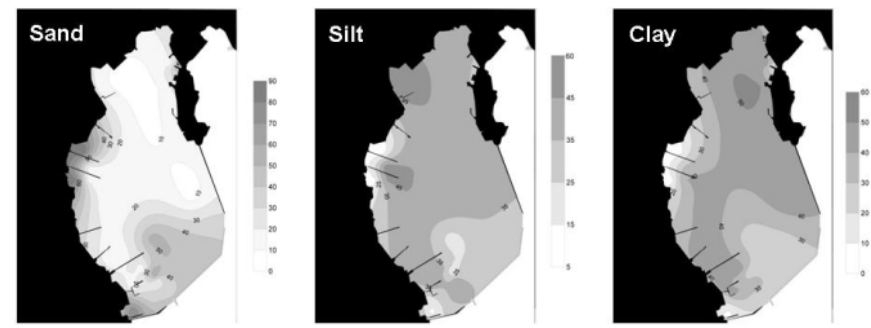

Fig. 2. Contour maps of sand, silt and clay content (\%) in surface sediments (Celia Magno et al., 2012).

\section{Technical features of the corers}

The gravity corer SW-104 (GVT) and vibro corer Rossfelder ${ }^{\circledR}$ (VBR) were used to collect sediment cores in the Augusta harbour (Fig. 3).

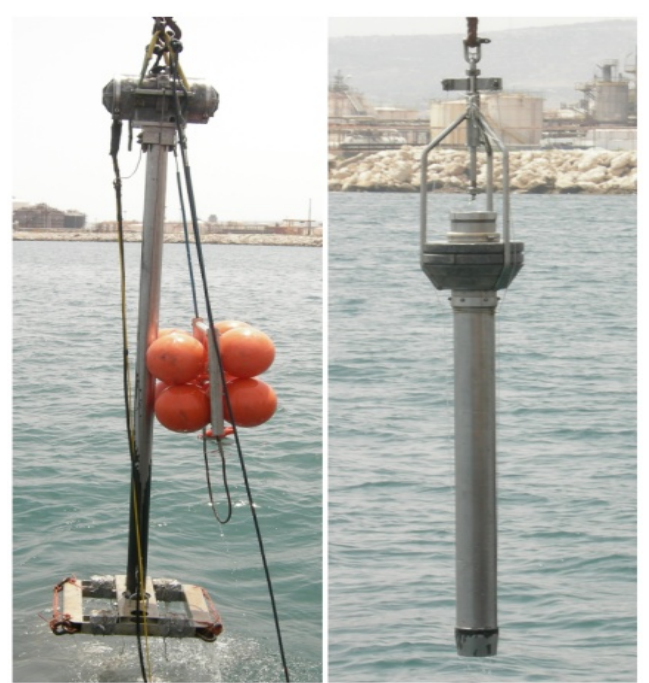

Figure 3. Rossfelder ${ }^{\circledR}$ vibro corer on the left and SW104 gravity corer on the right (Photo by ISPRA).

The SW-104 gravity corer is a suitable device for sampling mainly muddy sediments, but also the sandy ones; it can be used in sedimentary deposits of marine coastal area, but also in lagoon or prodelta areas and in the lakes. The corer used in this study was equipped with core tube containing an internal liner, $135 \mathrm{~cm}$ in length, with $104 \mathrm{~mm}$ internal diameter. The core sediment and bottom water are contained through a lower barrier of duck closing device and an upper water-containment valve. The core tube supports the dead weight, which provides the kinetic energy needed to penetrate sediments, and the governer, that controls the vertical descent of the corer, which generally occurs at speed ranging from 0.2 to $1 \mathrm{~m} \mathrm{sec}^{-1}$. At the end of the tube, the stainless steel nose is composed of a very sharp conical tip, to facilitate the penetration into the seabed (Magagnoli and Mengoli, 1995, 2000; National Research Council, 2013).

The Rossfelder ${ }^{\circledR}$ vibrocorer is commonly used to collect cores in a variety of sediment mixtures, from fine to coarse grain size. It has a vibrating mechanism at the head end, called "vibrohead", which operates on electrical power from an external source. The attached core tube is driven into sediment by the force of gravity, enhanced by vibration energy. The vibrocorer incorporates a tight-sealing water-escape valve mounted within the vibro-head, while a core catcher holds the corer during recovery (EPA, 2001). At the 
base of the tube there is a square base allowing vertical penetration in sediments An internal liner (90 mm internal diameter and $300 \mathrm{~cm}$ length), was utilized for the sampling of the sediments in the Augusta harbor.

\section{Materials and methods}

Gravity cores were sub-sampled by extrusion, while vibro cores were sampled following longitudinal splitting. Samples for geochemical and grain size analyses were carried out on 3-cm resolution. Parameters considered for this study were grain size, Mercury (Hg), Barium (Ba), Polychlorobiphenyls (PCBs) and Polycyclic Aromatic Hydrocarbons (PAHs). A duplicate of two cores (AU3, AU10) were used for the determination of sedimentation rates through geochronological analyses.

Samples for grain size analysis were previously treated with a $30 \% \mathrm{H}_{2} \mathrm{O}_{2}$ solution and then separated by wet sieving. The coarse fraction ( $>63 \mu \mathrm{m}$ ) was dried and fractionated by ASTM series sieves, while the finer one $(<63 \mu \mathrm{m})$ was analyzed by X-ray Sedigraph which identified silt and clay fractions. The $>63 \mu \mathrm{m}$ fraction was also observed under a stereomicroscope to recognize the main constituents (Romano et al., 2013). Sediment types were classified according to the ternary classification Shepard (1954).

Barium was analyzed on bulk sediment by means of microwave-assisted digestion using homogenized sample aliquots after oven-drying at $35^{\circ} \mathrm{C}$ for $48 \mathrm{~h}$. Instead, Hg was analyzed by means of a Direct Mercury Analyzer (DMA-80, FKV) through direct atomic absorption with gold amalgamation without chemical pretreatment (Maggi el al., 2009). Quantification limits were: $0.01 \mathrm{mg} \mathrm{g}^{-1}$ for $\mathrm{Hg}$ and $1.5 \mathrm{mg} \mathrm{g}^{-1}$ for Ba. PCBs were analyzed as $<2 \mathrm{~mm}$ homogenized, freeze dried samples and then extracted by pressurized fluid extraction using a Dionex model ASE 200 instrument. The determination was performed by high-resolution gas chromatography with electron capture detection (GC/ECD) in dual column-dual detector mode. The quantification limit was $0.00001 \mathrm{mg} \mathrm{kg}^{-1}$ (Bergamin et al., 2009).

The geochronological study was carried out at GAU laboratory (Southampton University), using the ${ }^{210} \mathrm{~Pb}$ and ${ }^{137}$ Cs methods, in order to determine sedimentation rates (Croudace et al., 2015).

The Pearson index ( $\mathrm{r}$ ) was calculated in order to recognize the correlations of GVT and VBR profiles of chemical and grain size parameters. The cross correlation was applied to the two series of selected data acquired by GVT and VBR at the same station, as a measure of similarity as a function of the displacement of one relative to the other (Campbell et al., 1996; Rose et al., 1999). Only parameters showing significant linear correlation of GVT and VBR profiles were considered for cross correlation. Statistical analysis was carried out by means of PAST (Hammer et al., 2001).

\section{Results}

In all the sampled cores, the chemical results highlighted heavy contamination, mainly due to Hg and PCBs. Core AU3 was sampled for 83 and $195 \mathrm{~cm}$ by GVT and VBR, respectively. The pelitic content $(<63 \mu \mathrm{m})$ ranges from 60 to $94 \%$ in the first one and from 55 to $88 \%$ in the second one. Chemical parameters display similar patterns, with higher values in the upper $25 \mathrm{~cm}$ (Ba up to $191 \mathrm{mg} \mathrm{kg}^{-1}$; Hg up to $11.9 \mathrm{mg} \mathrm{kg}^{-1}$; PCBs up to $0.08 \mathrm{mg} \mathrm{kg}^{-1}$ ) and around $118 \mathrm{~cm}$ (Ba up to $231 \mathrm{mg} \mathrm{kg}^{-1}$; $\mathrm{Hg} 16.7 \mathrm{mg} \mathrm{kg}^{-1}$; PCBs up to $0.12 \mathrm{mg} \mathrm{kg}^{-1}$ ); the last one was detected only by VBR (Fig. 4). 


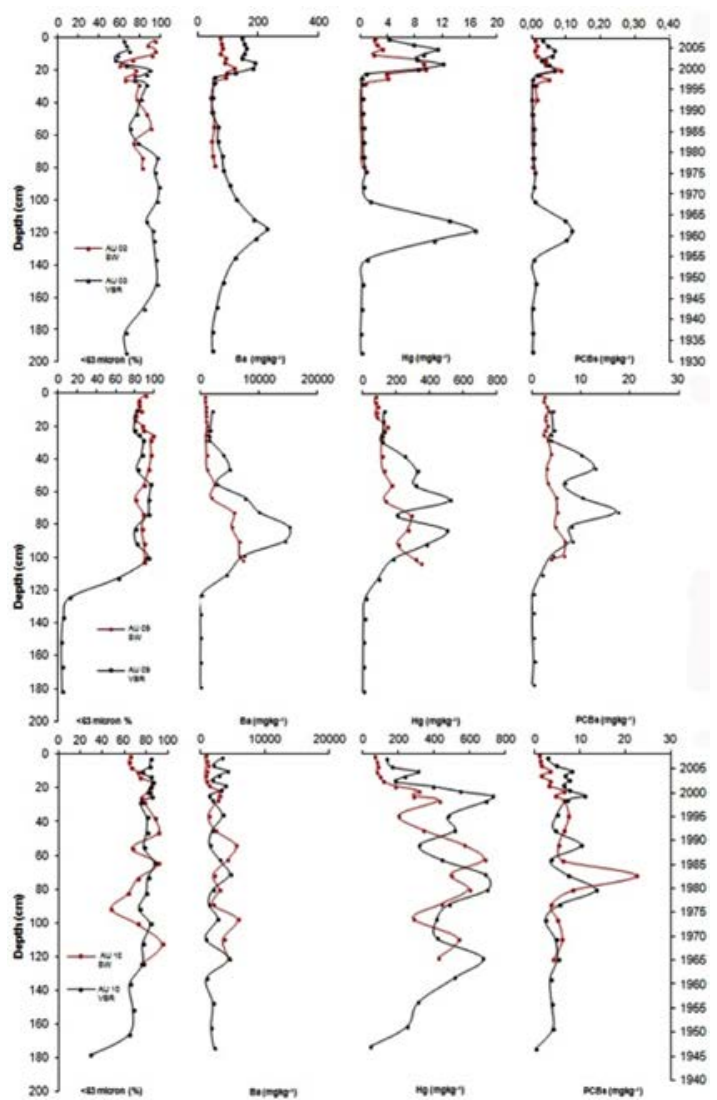

Figure 4. Downward profiles of < $63 \mu \mathrm{m}$ sediment fraction, Ba, $\mathrm{Hg}, \mathrm{PAHs}$ and PCBs in GVT and VBR replicates at AU3, AU9 and AU10 stations.

According to the geochronological determination, the lower peak corresponds to a main event occurred in the early 1960, which was a period of great development for the industrial site, while the upper enrichment ranges from 1995 to 2003. Only in the VBR core uncontaminated sediments below $150 \mathrm{~cm}$, older than late 1950s, were detected. High correlation degree $(r=0.577-0.877)$ of GVT and VBR chemical profiles were found to indicate a very good correspondence.

In the station AU9, GVT and VBR cores reached different sampling depth (104 and $183 \mathrm{~cm}$, respectively), with a pelitic content around 90\% in both cores. High contaminant levels were recognized between 50 and $100 \mathrm{~cm}$, with higher concentrations shown by VBR profiles (Ba up to $15133 \mathrm{mg} \mathrm{kg}^{-1}$; $\mathrm{Hg}$ up to $517.8 \mathrm{mg} \mathrm{kg}$ ${ }^{1}$; PCBs up to $17.22 \mathrm{mg} \mathrm{kg}^{-1}$ ). A dramatic decrease of fine sediment fraction and contaminant concentrations was detected only by VBR core below $120 \mathrm{~cm}$, where reference conditions may be recognized by vertical profiles (Fig. 4). Ba is the only parameter showing high correlation $(r=0.824)$ of GVT and VBR profiles. For core AU10, the depths of penetration for GVT and VBR were 126 and $180 \mathrm{~cm}$, respectively. In the common interval, GVT core shows higher variability of pelitic content (48-94\%) with respect to VBR core (75-85\%). Chemical parameters display very high comparable concentrations for both GVT (Ba up to 5707 $\mathrm{mg} \mathrm{kg}^{-1}$; $\mathrm{Hg}$ up to $680 \mathrm{mg} \mathrm{kg}^{-1}$; PCBs up to $22.56 \mathrm{mg} \mathrm{kg}^{-1}$ ) and VBR (Ba up to $4370 \mathrm{mg} \mathrm{kg}^{-1}$; $\mathrm{Hg}$ up to 728 $\mathrm{mg} \mathrm{kg}^{-1}$; PCBs up to $13.52 \mathrm{mg} \mathrm{kg}^{-1}$ ) profiles above $120 \mathrm{~cm}$, although the upper core level show a decrease for most parameters. A clear decrease of concentrations was recorded at the bottom level of VBR core. Hg is the only parameter showing significant correlation $(r=0.592)$ of GVT and VBR profiles.

The cross correlation was applied to the two series (GVT and VBR) of the same parameter for Ba, Hg and PCBs, in order to compare the similarity of their profiles, also taking into account the possible lag of one signal relative to the other, due to different characteristic of two devices (Hammer et al., 2001). Core AU3 showed the ideal condition to investigate the possible displacement the GVT and VBR data series, because 
good correlation (Pearson) was previously recognized for the two profiles. Very similar diagrams with high correlation values resulted for the considered parameters, indicating similar patterns for GVT and VBR profiles (Fig. 5). The highest correlations concentrated around 1-2 lag, corresponding to 3-6 cm according to sub-sampling resolution, indicates only a slight relative shift toward the top of VBR profiles. Cross correlation testifies also that no downward shift of contaminants, due to percolation, is recognizable in the VBR core.
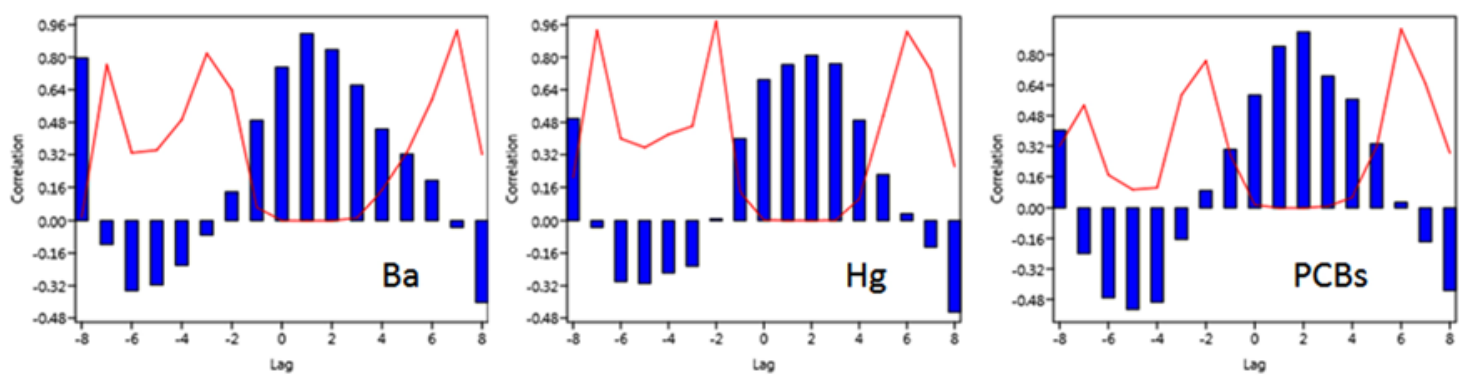

Figure 5. Output of cross correlation applied on Ba data of the GVT and VBR replicates at AU3 station (blue bars are correlation values; red lines are $p$ values).

\section{Discussion}

The prevalence of fine sediment fractions recognized in the three studied cores may be attributable to the harbour setting, closed by dams with only two inlets that ensure water exchange determined by tidal currents. The prevailingly sandy sediment recovered in AU9 below $120 \mathrm{~cm}$ may be considered as the natural sea bottom before the development of the industrial area and the construction of the dams. The results of chemical parameters from the three cores indicate a strong contamination degree for Ba, Hg and PCBs, mostly in the southern sector, attributable to the activity of the MCCAP, which left a strong contamination legacy also after its enclosure and removal of mercury cells in 2005 (Romano et al., 2013; 2016).

The comparison of vertical profiles, in gravity and vibro cores, of grain size, Ba, Hg and PCBs in AU3, AU9 and AU10 stations, allows making some considerations on advantages and disadvantages of the two different devices. It was clear in all the 3 cores that the penetration capacity of VBR was higher than GVT. Especially for AU3 and AU9, the use of VBR allowed sampling the older uncontaminated sediments, below 150 and $140 \mathrm{~cm}$, respectively (Fig. 4). The natural section of cores is characterized by low and scarcely variable concentration of metals and organic contaminants. The age of these levels, according to sedimentation rates up to $33 \mathrm{~cm} \mathrm{y}^{-1}$, determined by a previous study for cores AU3 and AU10, are older than 1950, when industrial activities started (Croudace et al., 2015). The recovery of sediments not affected by anthropogenic influence is of basic importance for the environmental assessment, which identifies the extent of deviation from natural condition, and for the identification of local background levels of metals and trace elements (Romano et al., 2015; Birch, 2017).

The higher similarity of GVT and VBR profiles both considering pattern and concentration values at AU3 station may be explained by the lower degree of physical and chemical anthropogenic impact in the central sector of the harbor, with respect to the southern one, which seems to determine high spatial variability and patchy distribution of chemical and textural characteristics of sediment (Romano et al., 2013).

The cross-correlation was considered in this study because it was previously demonstrated to be an effective tool to compare profiles of sediment parameters in different sediment cores (Rose et al., 1999; Iorio et al., 2004). It was used for comparing the vertical profiles of chemical concentrations, highlighting their correlation degree, attributable to the similarity of patterns along the core, and a potential relative displacement of profiles determined by different sampling methods. The slight upward shift of VBR profiles recorded in AU3 cores recognized by means of cross correlation, may be interpreted as a slight relative compaction in VBR core, which is probably due to its lower core diameter (Magagnoli and Mengoli, 1995). 
This problem may be at least in part reduced by principle of functioning of VBR because frequency vibration transfers more energy to the sediment, greatly reducing wall friction both inside and outside of the tube. Moreover, some additional compaction may be supposed also for GVT, due to the extrusion method adopted for sub-sampling. The relative compaction of 3-6 cm of VBR profiles may be considered of scarce importance considering the high sedimentation rates of the area.

Finally, the good correlation of GVT and VBR profiles let us exclude significant downward transfer of contaminants in both cores.

\section{Conclusion}

The Rossfelder ${ }^{\circledR}$ corer demonstrated the capacity of sampling a wide range of sediment types, collecting deep sandy levels below the pelitic layer at AU9 station. Only this corer demonstrated sufficient penetration capacity to sample deep levels $(140-180 \mathrm{~cm})$ corresponding to pre- industrial times in the study area, necessary for identification of reference conditions and the assessment of the environmental status A slight relative upward shift ( $3-6 \mathrm{~cm}$ ) of profiles of chemical concentrations, indicating slight sediment compaction for Rossfelder ${ }^{\circledR}$ corer, probably due to the lower core diameter with respect to the diameter of SW104. However, this compaction may be considered of scarce importance considering the high sedimentation rates of the area. Moreover, due to the good agreement of the profiles obtained with the two sampling methods, no downward shift of contaminants due to water percolation was recognized from chemical profiles.

Considering these results on the whole, we may conclude that the Rossfelder ${ }^{\circledR}$ corer is the best choice for the acquisition of sediment samples for environmental studies in marine coastal areas characterized by considerable sediment texture variability and high sedimentation rate.

\section{References}

Anonymous, 1992. Sistema integrato per il monitoraggio automatico della rada di Augusta. Studi preliminari per il posizionamento di boe oceanografiche. Istituto Sperimentale Talassografico CNR Messina, Rapporti 6: 1-120.

Anonymous, 1995. Studio sedimentologico e bionomico dei fondi mobili della Rada di Augusta. Istituto Sperimentale Talassografico CNR Messina, Rapporti 9: 1-72.

Bergamin, L., Romano, E., Finoia, M.G., Venti, F., Bianchi, J., Colasanti, A., Ausili, A., 2009. Benthic foraminifera from the coastal zone of Baia (Naples, Italy): Assemblage distribution and modification as tools for environmental characterization. Marine Pollution Bulletin 59 (8-12), 234-244.

Birch, G.F., 2017. Determination of sediment metal background concentrations and enrichment in marine environments - A critical review. Science of Total Environment 580, 813-831.

Campbell, J.Y., Lo, A.W., MacKinlay, A.C., 1996. The Econometrics of Financial Markets. Princeton University Press, New York, USA.

Celia Magno, M., Bergamin, L., Finoia, M.G., Pierfranceschi, G., Venti, F., Romano, E., 2012. Correlation between textural characteristics of marine sediments and benthic foraminifera in highly anthropogenically-altered coastal areas. Marine Geology 315-318, 143-161.

Croudace, I.W., Romano, E., Ausili, A., Bergamin, L., Rothwell, R.G., 2015. X-Ray core scanners as an environmental forensics tool: a case study of polluted harbour sediment (Augusta bay, Sicily). In: Croudace, I.W. and Rothwell, G., (Eds.), Micro-XRF Studies of Sediment Cores, Springer Developments in Environmental Research, Springer, Berlin, 393-421.

EPA, 2001. Methods for collection, storage and manipulation of sediments for chemical and toxicological analyses: Technical manual EPA-823-B-01-002.

Guo, Y., Yang, S., 2016. Heavy metal enrichments in the Changjiang (Yangtze River) catchment and on the inner shelf of the East China Sea over the last 150 years”. Science of Total Environment 543, 105-115. 
Hammer, Ø., Harper, D.A.T., Ryan, P.D., 2001. PAST: Paleontological Statistics Software Package for Education and Data Analysis. Palaeontologia Electronica 4, 9 pp.

ICRAM, 2008. Progetto preliminare di bonifica della rada di Augusta inclusa nel sito di bonifica di interesse nazionale di Priolo Fase I e Fase II. Report. BoI-Pr-SI-PR-Rada di Augusta-03.22, Internal Report

Iorio M., Sagnotti, L., Angelino, A., Budillon, F., D’Argenio, B., Dinare`s-Turell, J., Macrì, P., Marsella, E., 2004. High-resolution petrophysical and palaeomagnetic study of late-Holocene shelf sediments, Salerno Gulf, Tyrrhenian Sea. The Holocene 14(3), 426-435.

ISPRA, 2011. Note illustrative della Carta Geologica d'Italia, scala 1:50.000, Foglio 641 Augusta, 248.

Magagnoli, A., Mengoli, M., 1995. Carotiere a gravità SW-104 per carote di sedimento e acqua di fondo di grande diametro e minimo disturbo. Rapporto Tecnico IGM N. 27, 45 pp.

Magagnoli, A., Mengoli, M., 2000. Un brevetto CNR per la campionatura dei fondali marini. In: Bonatti, E., Gasperini, L., Ligi, M. Ravaioli, M. (Eds.), I due terzi oscuri del nostro Pianeta: la geologia della Terra sommersa. Ricerca \& Futuro 14, 67-68.

Maggi, C., Berducci, M. T., Bianchi, J., Giani, M., Campanella, L., 2009. Methylmercury determination in marine sediment and organisms by Direct Mercury Analyser. Analytica Chimica Acta 641, 32-36.

National Research Council, 2013. Final report of the oceanographic survey Nextdata 2013. Project NEXTDATA WP-1.5. Paleoclimatic Data from Marine Sediments. CNR-DTA, URT EvK2-CNR, INGV, Strait of Sicily - Gulf of Taranto. Technical Report, 16 pp.

Nigro, F., Renda, P., 2000. Un modello di evoluzione tettono-sedimentaria dell'avanfossa neogenica Siciliana. Bolletttino Società Geologica Italiana 119, 667-686.

Romano, E., Bergamin, L., Ausili, A., Celia Magno M., Gabellini, M., 2016. Evolution of the anthropogenic impact in the Augusta Harbor (Eastern Sicily, Italy) in the last decades: benthic foraminifera as indicators of environmental status. Environmental Science and Pollution Research 23(11):10514-10528.

Romano, E., Bergamin, L., Celia Magno, M., Ausili, A., 2013. Sediment characterization of the highly impacted Augusta harbour (Sicily, Italy): modern benthic foraminifera in relation to grain-size and sediment geochemistry. Environmental Science: Processes Impacts 15, 930-946.

Romano, E., Bergamin, L., Croudace, I.W., Ausili, A., Maggi, C., Gabellini, M., 2015. Establishing geochemical background levels of selected trace elements in areas having geochemical anomalies. The case study of the Orbetello lagoon (Tuscany, Italy)”. Environmental Pollution 202, 96-103.

Romano, E., Bergamin, L., Finoia, M.G., Celia Magno, M., Ausili, A., Gabellini, M., 2009. The effects of human impact on benthic foraminifera in the Augusta harbour (Sicily, Italy). In: Dahl, E., Moksness, E., Støttrup, J. (Eds.), Proceedings of the International Symposium on Integrated Coastal Zone Management. Wiley-Blackwell, Chichester, UK, pp. 97-115.

Rose, N.L., Harlock, S., Appleby, P.G., 1999. Within-basin profile variability and cross-correlation of lake sediment cores using the spheroidal carbonaceous particle record. Journal Paleolimnology 21, 85-96.

Scicchitano, G., Monaco, C., Tortorici, L., 2007. Large boulder deposits by tsunami waves along the Ionian coast of south-eastern Sicily (Italy). Marine Geology 238, 75-91.

Shepard, F.P., 1954. Nomenclature based on sand-silt-clay ratios. Journal of Sedimentary Petrology 24, 151158.

Sprovieri, M., Oliveri, E., Di Leonardo, R., Romano, E., Ausili, A., Gabellini, M., Barra, M., Tranchida, G., Bellanca, A., Neri, R., Budillon, F., Saggiomo, R., Mazzola, S., Saggiomo, V., 2011. The key role played by the Augusta basin (southern Italy) in the mercury contamination of the Mediterranean Sea. Journal Environmental Monitoring 13, 1753-1760. 